With 2 plates

\title{
A scanning electron microscope study of the male copulatory sclerite of the monogenean Diplectanum aequans
}

\author{
C. MAILLARD ${ }^{1}$, J. GONZALEZ ${ }^{2}$ and D. NOISY ${ }^{2}$ \\ 1 Laboratoire de Parasitologie Comparée, E.R.A. 915, Universilé des Sciences et \\ Techniques du Languedoc, Pl. E. Bataillon, 34060 Montpellier Cedex, France. \\ ${ }^{2}$ Institut de Biologie animale, Palais de Rumine, 1005 Lausanne, Switzerland.
}

(Accepted 26 June 1981)

S UM M ARY

The cirrus of a monogenean Diplectanum aequans was isolated by treatment with sodium carbonate solution and studied with a scanning electron microscope. The method may be used in studies of the functional morphology and taxonomy of other organisms.

\section{INTRODUCTION}

Sclerotized structures are frequently used in both specific identifications and phylogenetic studies of helminths. Among the sclerites used for such purposes in monogeneans are the male copulatory organs; these appear not to be subject to the same degree of adaptative variation as the sclerites of adhesive organs. However, some of the copulatory sclerites are complex and have an intricate 3-dimensional structure, the details of which are at the limit of resolution of the light microscope.

It was decided therefore to explore the use of the scanning electron microscope (S.E.M.) in elucidating the detailed structure of some sclerites and, mainly because of the availability of the Bass Dicentrachus labrax $L$. which is cultivated commercially in the south of France, its very common monogenean gill parasite Diplectanum aequans (Wagener) was selected for our pilot study.

\section{MATERIALS AND METHODS}

After considerable trials the following method for fresh parasites was evolved. Specimens were fixed for $24 \mathrm{~h}$ in $70 \%(\mathrm{v} / \mathrm{v})$ ethanol and were then treated with a $40 \%(w / v)$ solution of sodium carbonate for about $6 \mathrm{~h}$ to dissolve intercellular cement. They were transferred to a cover-slip previously coated with a thin layer of dilute rubber cement and excess sodium carbonate was removed with a pipette. A drop of distilled water was added to disrupt the parasite and disperse the sclerites. The water was allowed to evaporate, leaving the sclerites stuck by the mubber cement to the slide. Cell debris was removed by washing and the specimens were finally coated with metal, in the usual way, for scanning electron microscopy.

\section{RESULTS}

As a result of treating specimens of $D$. aequans by the method described, the cirrus, hamuli and transverse bars were isolated but the other sclerites, namely the spines of the squamodiscs and the marginal hooks, were never recovered. 
The treatment with sodium carbonate appcared to dissolve material from within the hamuli, but the other sclerites recovered appeared to be undamaged.

When examined with the S.E.M. the transverse bars yielded only a few details of structure beyond those revealed by light microscope studies, but much new information was obtained about the male copulatory organ, especially in regard to its distal region (Pl. 1 A). The distal part tapers, then is recurved (Pl. 1 B) and hollowed into a spoon (Pl. 1C). In the concavity of some specimens an orifice is seen which is probably that of the canal running throughout the organ ( $\mathrm{Pl}$. $1 \mathrm{D}$, arrow). The outer border of this zone, the flange, bears teeth which vary, in different individuals, in their number, form and arrangement.

Near the distal end of the male sclerite there is always an isolated tooth lying in a different plane from that of the more proximal teeth (Pl. $2 \mathrm{~B}, \mathrm{C}$ ). The proximal teeth vary in number and it is possible to recognize two types of dentition, one in which the flange bears 5-7 teeth restricted to the mid-region of the flange (PI. $2 \mathrm{~A}, \mathrm{C}$ ) and another in which there is a complete row of 9-12 teeth (PI. 2 B, D).

\section{DISCUSSION}

The use of the S.E.M. has provided new information about the detailed structure of the male sclerite. This could lead to a better understanding of the functioning of this organ, for example, a possible relationship between its shape and that of the spermatophores produced by this parasite (Paling, 1966). Again, a variation was discovered in the arrangement and number of teeth at the distal end of the male sclerite, and it is possible that these variations could be of use, for example, in comparing specimens of $D$. aequans from different geographical locations.

Further work will be necessary to overcome the difficulties we experienced in recovering certain selerites, but the method is promising and may be capable of application to other parasites.

We are grateful to Professors I. Fuzet and J. Lleweliyn for their help and useful criticisms in the preparation of this paper.

\section{REF ERE NCE}

PaLing, J. E. (1966). The functional morphology of the genitalia of the spermatophore-producing monogenean parasite Dipleclanum aequans (Wagener) Diesing, with a note on the copulation of the parasite. Parasitology 56, 367-83.

\section{EXPLANATION OF PLATES}

$$
\text { Plate } 1
$$

A. The cirrus of Diplectanum aequans in toto.

C.D. Distal end of the cirrus of several specimens of Diplectanum aequans observed from different angles.

Plate 2

A-D. Distal end of the cirrus of several specimens of Dipleclanum aequans observed from different angles.

$$
\text { Printed in Great Britain }
$$



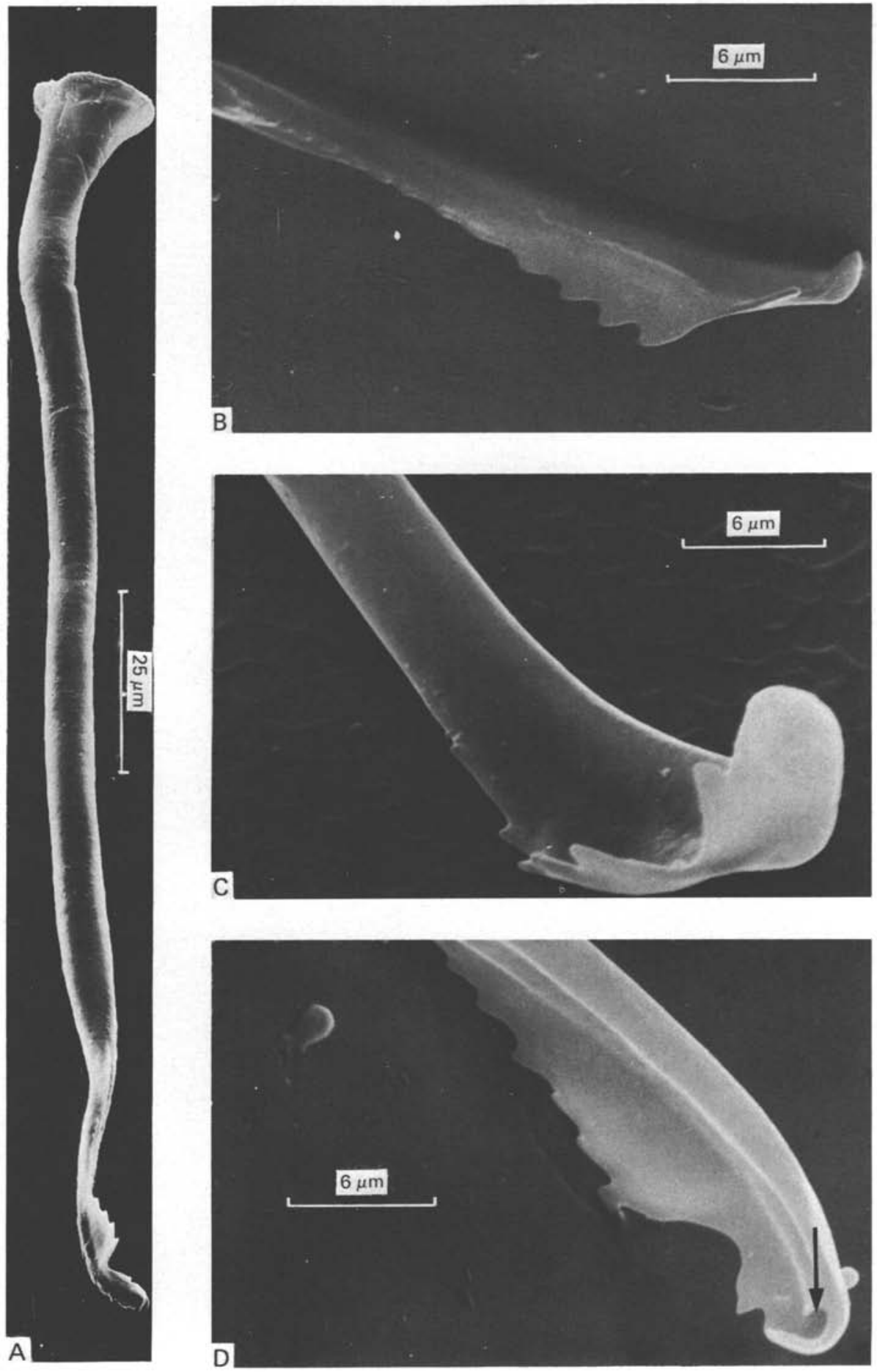

C. MAILLARD, J. GONZALEZ AND D. NOISY

(Facing p. 64) 

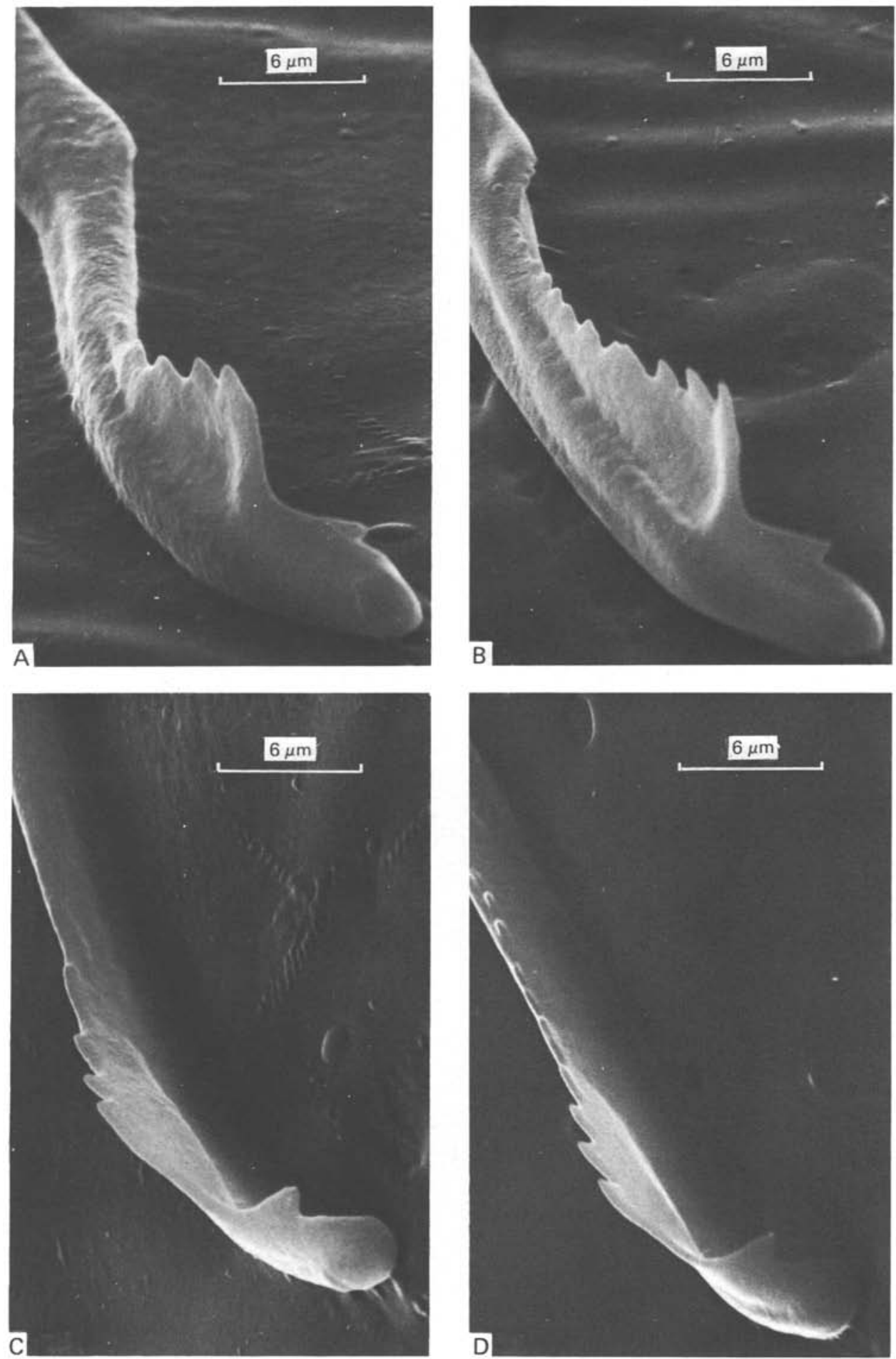

C. MAILLARD, J. GONZALEZ AND D. NOISY 